\title{
A Novel Finite Element Model Updating Method Based on
}

\section{Substructure and Response Surface Model}

\author{
Deshan Shan*, Qiao Li,Inamullah Khan and Xiaohang Zhou \\ (Bridge Engineering Department, Southwest Jiaotong University, Chengdu, Sichuan610031, China)
}

\begin{abstract}
:
Combining the substructure finiteelement model updating method with the response surface model updating method, one novel finite element model updating method of bridge structure is proposed for updating the finite element model of a certain combined cable-stayed suspension model bridge. In light of specific configurations and mechanical features for combined cable-stayed suspension bridge, substructures are partitioned and the updatingdesign parameters which need to be updated are preselected. On the basis of the variance analysis, the updating parameters are determined by the parameter significance test. Samples of updating parameters are obtained by the homogeneous design method, and the corresponding structural responses are obtained by finite element analysis, finally the response surface model for each updating parameter is fitted and verified. The jointed objective function with the linear combination of fitness functions based on the natural frequency and the static displacement are introduced, and experimental data of the static and dynamic testing for the model bridge is adopted to update the design parameters by the genetic algorithm, then the minimization of the discrepancies between the measurements and the finite element model updating results are achieved. The experimental results show that the updated parameters obtained from the proposed method are reasonable andtheir physical meanings are remained, and the finiteelement model of bridge structure can be updated effectively by the proposed finite element model updating method.
\end{abstract}

Keywords:Finite element model updating; Combined cable-stayed suspension bridge; Substructure; Response surface; Experimental validation

\section{Introduction}

It is indispensableto found the accurate finite element model of bridge structure for structural system identification, damage detection and load capacity assessment of real bridge structures [1].But the results of numerical simulation are generally inconsistent with the measured structural behavior for the reason of material property randomness, construction deviation, structural degradation or damage and some other factors[2].

Material properties, boundary constraints, field

*Corresponding author. Tel.: +8613608029847.

E-mail address:dsshan@home.swjtu.edu.cn measurements, etc. are the main reasons for the discrepancy between the structural response from the Finite Element Model and measured structural response, and quantification of these uncertainties is infeasible in term of large complex structure, such as bridge structure[3],[4].

Many finite element modelupdating methodsbased on optimization algorithm have been put forward tomakethe finite element modelconsistent with structural behavior measurements [5].Among the optimization-based model updating methods,there are mainly two categories,one is sensitivity-analysis-based (SA-based) algorithm and the otheris variance-analysis-based (VA-based) algorithm.

In SA-based finiteelement model updating methods, the measured structural responses 
areregarded as the perturbations ofdesign data about the original finite-element mode [5]. By calculating the relationship between the parameters and structural properties, the sensitivity of the parameters can be obtained[5]. Combining the sensitivity-based finite element model updating method with uncertainty analysis, the finite element model of a seven-story reinforced concrete wall building structure is updated by B. Moaveni et al.[6]; the finite element model of a certain concrete-filled steel tubular arch bridge is updated by B. Jaishi et al.[7]based on sensitivity analysis; the first-order Taylor-series expansion of the eigenvalues are applied to improve the sensitivity-based updating approach by Q.W. Zhang et al.[8], and the proposed method is verified by updating a $1 / 150$ scaled suspension bridge; The modal flexibility are adopted as the objective function, then the sensitivity-based method is employedby B. Jaishi et al.[9] to update the finite element model of a reinforced concrete beam; combining the sensitivity analysis with the two-levels neural network, Y. Lu et al. [10] improve the SA-based finite element model updating method, and a numerical case study is engagedto verify the proposed algorithm.

Based on the statistical analysis of the uncertainties of the structure and measurement, the VA-based model updated algorithmalso has a wide range of applications[5].As the commonly adopted VA-basedfinite element model updating method, response surface (RS) based finite element model updating method are getting more and more attention in the bridge engineeringcommunity [2]. The static[11] and dynamic[12] responsesare adopted as the objective function, then the response surface method is adopted by W.X. Ren et al. to update the finite element model of Hong Tang Bridge; the finite element model of Tarmar Bridge is updated by E.J. Cross et al[13],aided by RS-based model updating method, and the updated finite element model is adopted to analyze its long-term monitoring data; the RS model updating method based on the radial basis function is applied to update one cable-stayed model bridge byL.R. Zhouet al.[14]; combining the RS model updating method with genetic algorithm, the finite element model of one model bridge is updated by L. Deng[15]; utilizing the measured natural frequencies and mode shapes, RS-based method is adopted by X. Li et al [16], to update the finite element model of a certain concrete-filled steel tubular arch bridge, and the updated model is used to predict the structural seismic response.

SA-based algorithms aregenerally computationally intensive, and it is difficult to converge for the reason of iteration determination of local gradient [12].Many different approaches are proposed to decrease the computational requirement and improve the converge problem of SA-based algorithms[17][18], and satisfactory results have been achieved. On the other hand, in the VA-based algorithms, the relationship between preselected input and output parameters of the finite element model are carried out in light of the variance analysis of the preselected parameters, and the relationship shown in a mathematical expression, such as polynomial function, isconsideredas a surrogate model for the finite element model, then the parameters of the surrogate model is updated directly by the measured data [19].

As for as the complex structuresare concerned, such as combined cable-stayedsuspension bridge, the introduction of substructures can improve the computational efficiency of the model updating [5].One of themost popular and sophisticated method in dealing with the dynamic analysis of substructure is the component mode synthesis (CMS). It is commonly adopted in the mechanical analysis of large and complex structure which includesthe finite element model updating. The finite element model of a bowstring arch bridge is updated by Y. Liu et al[20], [21].Based on the CMS technique; using a high fidelitymodel and simulated measurements of a highway bridge, model updating and damage identification applications of CMS technique are demonstrated by Papadimitriou $\mathrm{C}$. et al [22] ;utilizing the long-term monitoring data from Dowling Hall Bridge,the substructure model 
updating method are adopted to update its finite element model byMoabeni B. et al[23]; substructure finite element updating method is discussed in detail by Weng S. et al [24],from the viewpointof sensitivity analysis; combination the substructure-based model updating method with the artificial neural network algorithm of radial basis function, the finite element model of a certain cable-stayed bridgewith single pylon and double cable-plane is updated by Dehao Ding[25]andDeshan Shanet al [26], respectively.All of the above mentioned substructure-based finite element model updating belongtosensitivity analysis based model updating methods. Furthermore, there are some additional requirements in the CMS technique based method, such as the coordination transform between the physical coordination and the mode coordination, different boundary conditions between components, etc.[20][22], and some extra skills are required to obtain the satisfactory results [27].

Based on the existed research of finite element model updating methods for bridge structure, and in light of the VA-based finite element model updating method [5], one novel finite element model updating method, which combined the substructure model updating method with RS-based model updating method,is proposed in this paper to update the finite element model of a certain combined cable-stayed suspension model bridge.

\section{Finite element model updating}

The substructure-based finite element model updating method is an effective method for large and complex structural finite element model updating [5].Based on the sensitivity analysis of design parameters, the design parameter is supposed to be a constant in each substructure in light of the substructure-based model updating method [5], thus it means that the design parameters are updated by regions. However, it is not feasible to achieve the global optimization[5]for the sake ofintensive computational effort in practical applications.
Based on variance analysis of uncertainties for design parameters, possible valuesof design parameterswithin reasonable limits are determined at first by adopting theresponse surface model updating method[12],[3],[11],[15], and the possible values of design parameters are termed as the sample points, thencorresponding structural responses to all of the sample points are figured out by initial finite element model.Furthermore, regression analysis [28]is utilized to fit the structural responses corresponding to predetermined sample points, and the response surface model of bridge structure to predict the structural response is obtained. Moreover, the fitted response surface model is regarded as a surrogate model of the finite element model in the subsequent process of the design parametersupdating.It means that the fitted response surface model of bridge structure is a kind meta-model of structural finite element model in nature [5].In comparison with the SA-based design parametersupdating methods,the parameter significance obtained by VA-based response surface model updating methodownsthe global property. When the response surface model updating method is applied to the finite element model updating of large and complex structures, the required number of sample points will be increased significantly along with theincreasing number of design parameters,and therefore it is difficult to obtain the rationalresponse surface model[5].

Based on the design parameters of finite element model updating theory, a novel finite element model updating approach, which combines the substructure-based model updatingwith the response surface model updating method, is proposed to update the finite element model of a certain combined cable-stayed suspension bridge. The flowchart of the proposed method is shown inFig.1. As shown in this figure, substructure partition,test design, significance test, fitting and validation of response surface function are the keys features of the proposed finite element model method. 


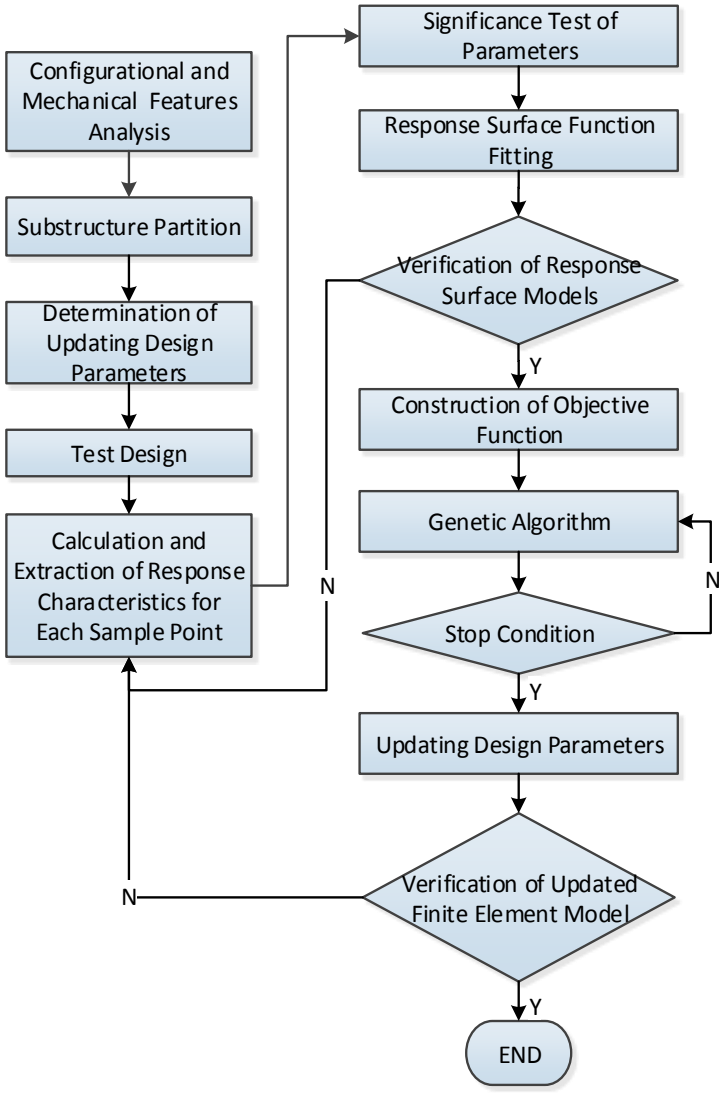

Fig.1. Flowchart of proposed FEM Updating method

\subsection{Substructure Partition}

During the finite element model updating, structures can be partitioned into groups of components that are called substructures to improve the computational efficiency [29],[30]. For bridge structure, it can be partitioned into substructures in a variety of forms, but the reasonable substructure partition has a direct impact on the efficiency and accuracy of the analysis results. According to the structural and mechanical characteristics of bridge structure and the design parameter based model updating theory [5], the substructure partition is implemented in the light of principles and methods shown in [31].

\subsection{Test Design}

The purpose of test design is to obtain the sample points of design parameters within their probable variation scopes. Two common test design methods of finite element model updating for bridge structure are orthogonal design and homogeneous design method. One specific application of Pseudo-Monte Carlo method is the homogeneous test design method[5], and is helpful to draw out the relationship between design parameters and their corresponding structural responses from the minimal number of tests, and the homogeneous test design method is more feasible asthe number of updating design parameters increases.

The construction process for a homogeneous designs table is listed as following:

1) Test count $n$ should be determined at first, $n$ can be equal to the parameter level,andall the integer $h_{i}(i=1,2, \ldots, m)$ less than nare all sought out with the greatest common divisor between $h_{i}$ and $n$ is 1 , then all $h_{i}$ are collected into a vector $\mathbf{h}=\left\{h_{1}, h_{2}, \ldots, h_{j}, \ldots, h_{m}\right\}$ in the ascending order.

2) The $u_{i j}$ at the $j$ th column in the homogeneous design table are carried out according to the Eq.(1)

$$
u_{i j}=i h_{i}[\bmod n]
$$

where, $[\bmod n]$ means modulus operator.

\subsection{Parametric Significance Test}

For obtaining the significance of any parameter in a model, a test statistic is carried out that is dependent on the estimated coefficient for that parameter. An F-test canbeusedto assess thesignificanceofaregressionmodelby the variance analysis of the independentvariables which are accountedfor in themodel.

To conduct the F-test, a new independent variable $x_{m}$ is added intoanestablishedregressionmodelwith $\quad m-1$ independent variables $x_{1}, x_{2}, \ldots, x_{m-1}$, thus resulted in a new augmented regression model. Then the improvement of the significance for the new augmented model is evaluated bycalculatingthe $F$ statistic shown in Eq.(2), whichisaratioofthevariance increment derived from the new added parametersto

themeansquarederroroftheaugmentedmodel.

$$
F_{m}=\frac{S S E_{m-1}-S S E_{m}}{S S E_{m} /(n-m-1)}
$$


where, $S S E_{m-1}$ and $S S E_{m}$ are the sumsof squared error for the regression modelswith m-1and mindependent variables respectively; $\mathrm{n}$ means the total number of independent variables in the regression model.

The null hypothesis of the F-test is that the prediction capability of the augmented model with new variables $x_{m}$ does not significantly improve,therefore giving rise to establish the regression model.Thishypothesisisrejectedata significance level $\alpha$ if the F-test statistic islargerthanthetabulated $\mathrm{F}$ value from $\mathrm{F}$-distribution.

\subsection{Fitting and Validation of Response Surface}

There are few mathematical formulas for the response surface function, such as first, second and third-order polynomials. Thequadratic incomplete polynomial is adopted to fit the response surface function in this paperthrough the comparative analysis of the above mentioned formulas, shown as follow:

$$
Y=\beta_{0}+\sum_{i=1}^{M} \beta_{i} E_{i}+\sum_{i=1}^{M} \beta_{i+N} E_{i}^{2}
$$

where, $M$ is the number of design parameters to be updated; $Y$ is the response surface function; $\beta_{i}(i=$ $0,1, \ldots, 2 M+1)$ is the undetermined coefficients in the function, and their values are determined through the polynomial regression analysisof the sample points obtained from the test design and the corresponding structural responses, as a result the fitted response surface models of structural responsesareachieved.

The fitted response surface models should be validated through their fitness, before adopting them to substitute the finite element model. Sum-of-Squares Error, Average Error, Maximum Error, R-square Statistic and Relative Mean Square Error are the common indexes for this kind of validation.
In this paper, R-square Statistic shown in Eq.(4)and Relative Mean Square Error shown in Eq.(5)are regarded as the criterions to check the fitness of the fitted response surface models.

$$
\begin{aligned}
R^{2} & =1-\frac{\sum_{j=1}^{N}\left[y_{R S}(j)-y(j)\right]^{2}}{\sum_{j=1}^{N}[y(j)-\bar{y}]^{2}} \\
\text { RMSE } & =\frac{1}{N \cdot \bar{y}} \cdot \sqrt{\sum\left[y_{R S}(j)-y(j)\right]^{2}}
\end{aligned}
$$

Where $y_{R S}$ is the function value of the obtained response surface model; yis finite element calculation results, $\bar{y}$ is the mean of $\mathrm{y}$; and $\mathrm{N}$ is the number of sample points. The value of R-square statistic value is between $0 \sim 1$, its value is more closed to 1 means the fitted response surface model is more approximate to the finite element model; and in contrast with the R-square statistic index, more closed to 0 for the RMSE value, better the fitted response surface model is.

\subsection{Objective function}

To takeinto consideration the maximumpart of the static and dynamic measurementsinthe procedure of the finite element model updating, and combining the fitness function of structural static responses [32] with the fitness function of structural dynamic property, a joint objective function shown in Eq.(6)is introduced.

$$
f(x)=\sum_{k=1}^{K}\left(1-\frac{D_{f k}}{D_{t k}}\right)^{2}+\sum_{l=1}^{L}\left(1-\frac{\omega_{f l}}{\omega_{t l}}\right)^{2}
$$

Where, $f(x)$ is objective function; $D_{f k}$ and $D_{t k}(k=1,2, \ldots, K)$ are the static displacementsat the displacement-measured points obtained from the finite element analysis and static experiment respectively; and $\omega_{f l}$ and $\omega_{f l}(\mathrm{l}=1,2, \ldots, L)$ are calculated and measured natural frequencies respectively. $K$ denotesthe number of displacementmeasuring points, $L$ is number ofnatural frequencies. 

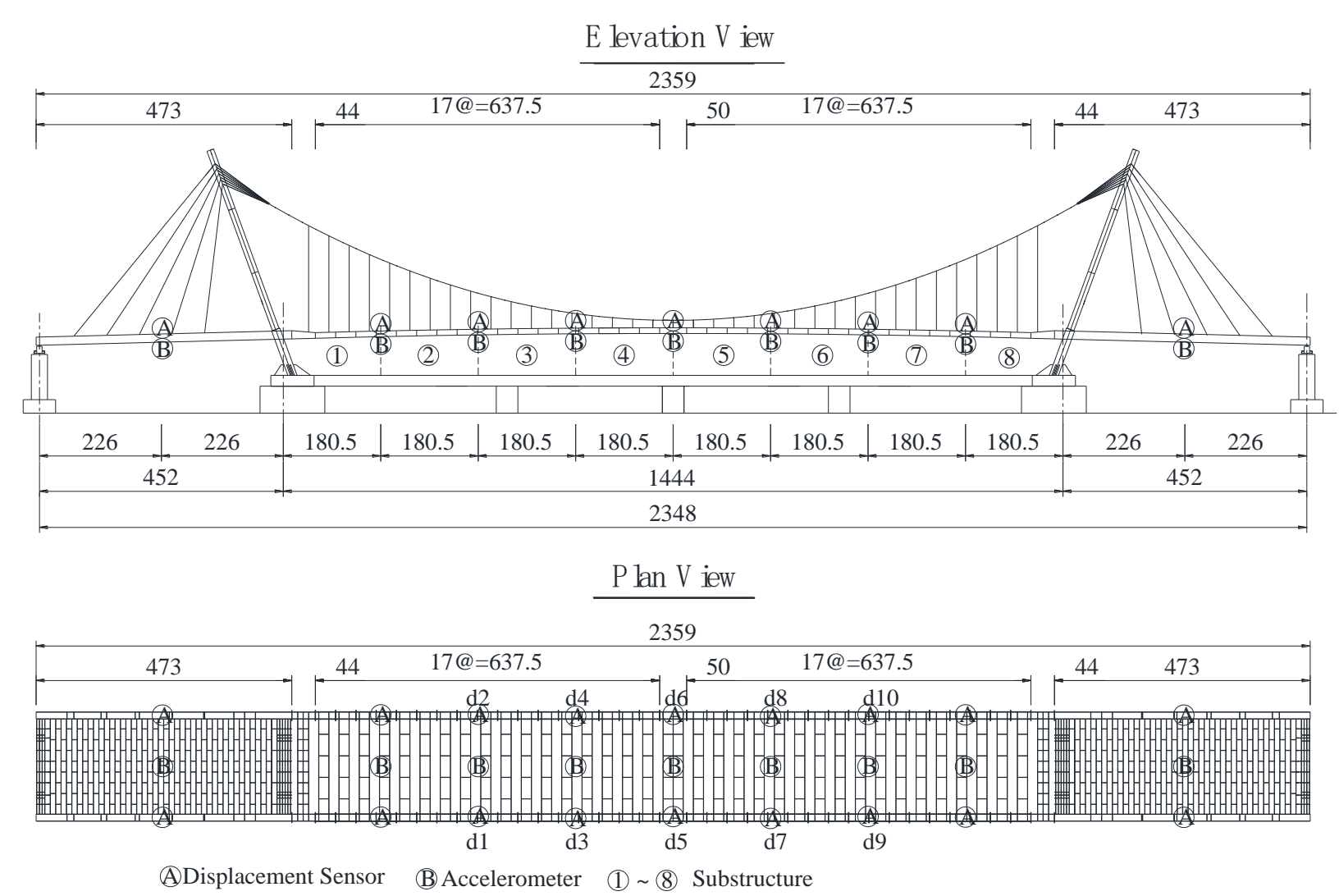

Fig.2.General arrangement of the combined cable-stayed suspension model bridge(unit: $\mathrm{cm}$ )
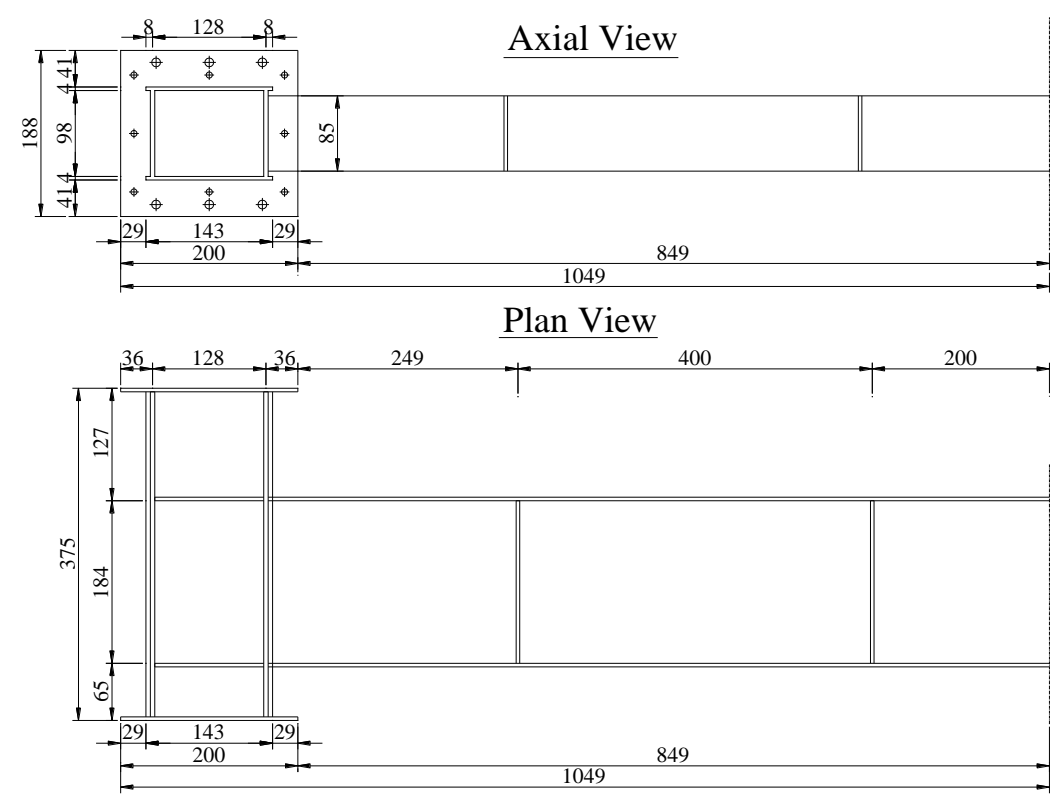

Fig. 3.Section form of main girder(unit: $\mathrm{mm}$ )

3. Combined cable-stayed suspension Model Bridge and Experiment

\subsection{Model Bridge}

The model bridge is a three span combined cable-stayed suspension bridge with cable-stayed structure for both side spans and suspension structure for middle span. The pylon with $3 \mathrm{~m}$ clear height is inclined $20^{\circ}$ to the side span,as shown in Fig.2, the span arrangement is $4.52 \mathrm{~m}+14.44$ $\mathrm{m}+4.52 \mathrm{~m}$, and the total length of the model bridge is $23.48 \mathrm{~m}$. There are 74 suspenders in the model bridge, and 37 suspenders for the upstream side and downstream side respectively. The distance between 
two adjacent suspenders is $37.5 \mathrm{~cm}$,except for the distance between two suspenders at middle span of main span is $50 \mathrm{~cm}$. There are 5 pairs stay-cable with $62.5 \mathrm{~cm}$ spacing for each side span, and the total number of stay-cable is 20 . Suspender and stay-cable are made of spring steel wire, and their diameters are $1.9 \mathrm{~mm}$ and $3.5 \mathrm{~mm}$ respectively. The main cable with spatial configuration of the model bridge is composed of $7 Ф 3.6 \mathrm{~mm}$ spring steel wire.

Both the girder and the pylon of thebridge are made of $\mathrm{Q} 235 \mathrm{C}$, and the girder is a lattice structure with both side stringers, longitudinal and horizontal stiffeners. There are four types of girder segment, i.e. A, B, C, D; A-type girder segment with $50.00 \mathrm{~cm}$ length is designed specifically for the girder at the middle of the main span; B-type girder segment with $37.50 \mathrm{~cm}$ length is the standard segment for the main span; and the whole girder of each side span are D-type girder segment with $473.40 \mathrm{~cm}$ length; C-type girder segment with $43.75 \mathrm{~cm}$ length is the joint segment between the B-type girder segment and the D-type girder segment. Hence, there are 1 and 34 segments for A-type beam segment and B-type girder segment respectively in the model bridge, and the both number of C-type and D-type girder segment are 2. Namely, there are 37 segments for main spangirder, 1 segment for side span, and the total number of girder segment is 39 . Allthe segments are manufactured in a mechanical processing factory, and are bolted together to form the girder of the model bridge in the laboratory, as shown inFig.4. The transverseconfiguration of the inclined pylon is an arch structure.The picture of the model bridge in the laboratory is shown inFig. 5 .

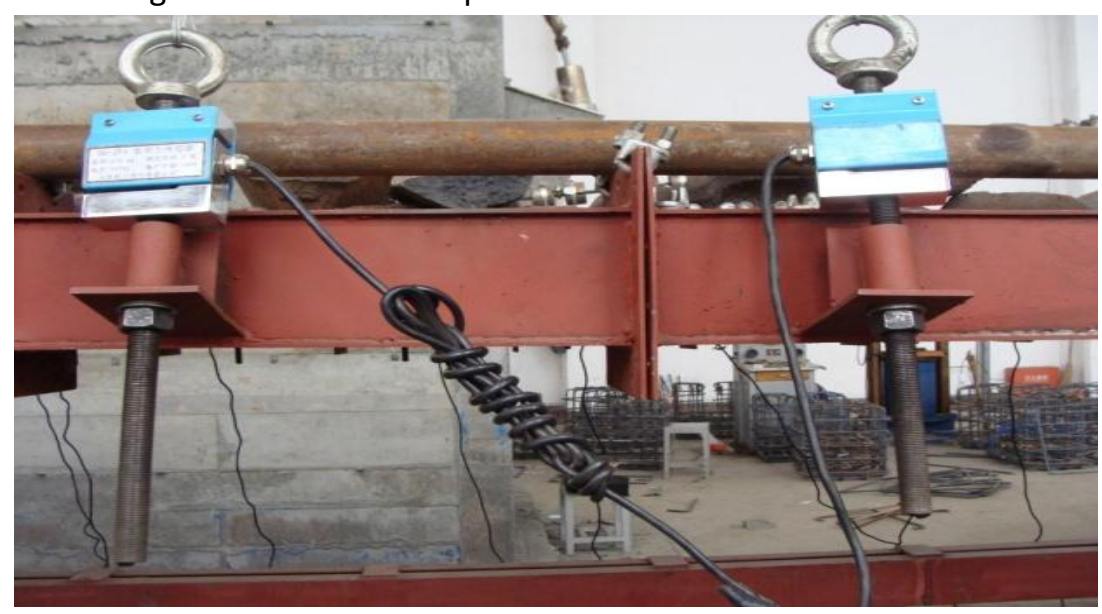

Fig.4. Photo of Main Girder Connection

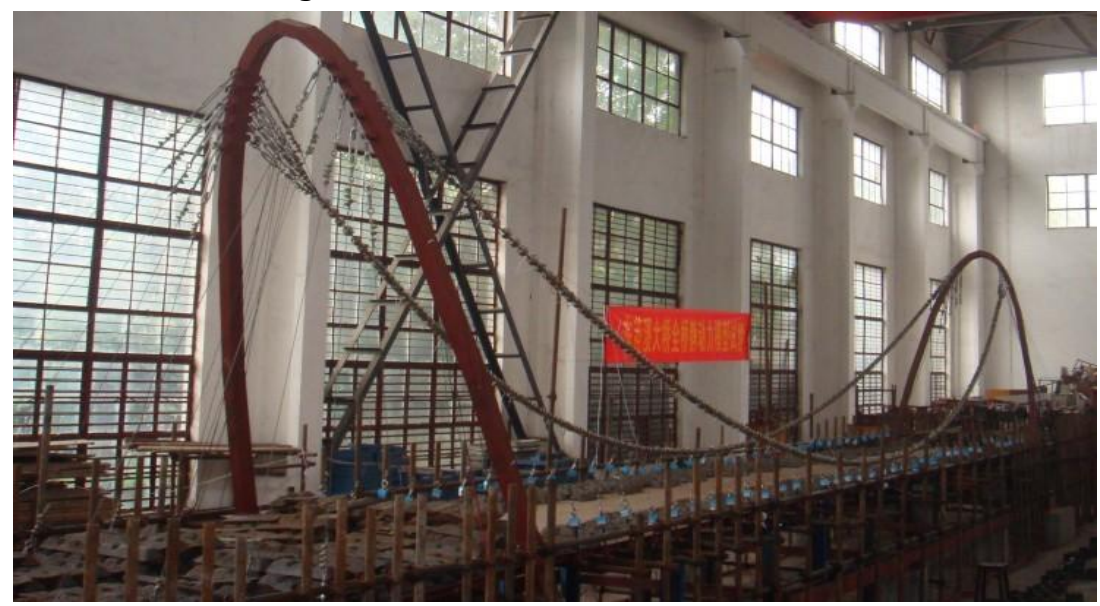

Fig.5. Model Bridge in Laboratory

\subsection{Sensor Layout}

The static loading test and ambient test are carried out on the model bridge to collect the measured-data 
for updating the finite element model of the model bridge. One individual force sensor is installed on each suspender, stay-cable and splayed-main cable to measure its cable force, and there are totally 122 force sensors instrumented on the cable components of the model bridge. Two dial indicators are installed on upstream and downstream sides of the main girder at $L_{1} / 2$ point of the each side span and on the $L_{2} / 8$, $L_{2} / 4,3 L_{2} / 8, L_{2} / 2,5 L_{2} / 8,3 L_{2} / 4$ and $7 L_{2} / 8$ point of the main span, and there are 18 dial indicators in total. In addition, the vertical accelerometer is installed on the transversal mid-position of the main girder at $L_{1} / 2$ point of the each side span and on the $L_{2} / 8, L_{2} / 4,3 L_{2} / 8, L_{2} / 2,5 L_{2} / 8,3 L_{2} / 4$ and $7 L_{2} / 8$ point of the main span, so the total number of accelerometers are 9. Where, $L_{1}$ and $L_{2}$ indicate the lengths of side span and main span respectively. The detail information of sensors layout isalready shown inFig.2.

BeeTech wireless data acquisition and transmission system is adopted to acquire the acceleration of the main girder, and CDJM automatic integral test system is utilized to obtain the cable forces and displacements of the main girder.

\section{Finite Element Model Updating of Combined Cable-Stayed Suspension Bridge}

\subsection{Initial Finite Element Model}

As shown inFig.4, segments of the main girder are bolted together at the end connection plate of each segments, and the mechanical behavior of the model bridge is obviously affected by this kind ofsegment connection. A real connection model with accurate simulation of the connection status between adjacent segments is established by ANSYS to carry out the mechanical behavior of the main girder. In this modelshell elements are used to simulate the gussets of the connection, then the connecting stiffness between two adjacent gussets is achieved by solving their contact problem, as shown inFig.7

a).The real connection model is time-consuming equivalent connection girderis taken as an in the calculation of this kind of complex bridge structure for the reason of shell element and contact problem. For improving the calculation efficiency,an equivalent connection model shown inFig.7b) of the main girder is established by using the cross-section of the stringer to substitute the cross section of connection plate, and the elastic modulus of the indeterminateparameter. After the analysis and comparison of the mechanical behaviors of these two connecting models, it is revealed that the elastic modulus of the equivalent connectiongirder is 0.827 times the steel elastic modulus, and the dynamic and static behaviors of these two models are consistent.

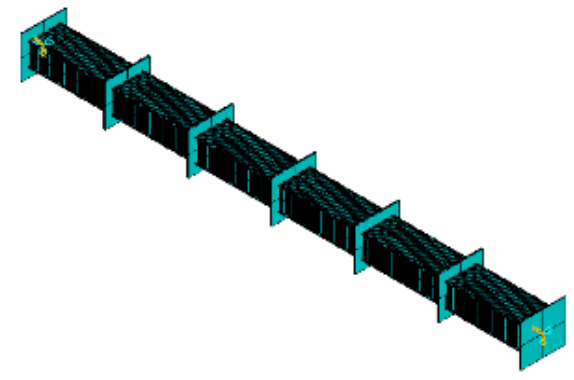

a)Real connection model

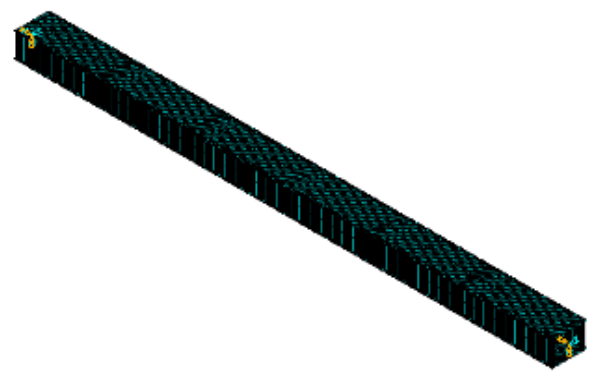

b) Equivalentconnection model

Fig.6. Connection Simulation of Main Girder

Then the equivalent connection model is adopted to figure out the 3-D initial finite element model of the combined cable-stayed suspension bridge in ANSYS as shown inFig.7.LINK180 Element with tension only option is adopted to simulate the main cable, splayed main cables, suspenders and stay-cables, and the total number of LINK180 is 197;
BEAM188 element is utilized to simulate the main girder and the pylons, so in total there are 5,438 element.Moreover, the counter weights on the girder and main-cable is considered as additional mass and simulated by MASS21 element, and the total number of MASS21 is 1,441 . Meanwhile, there are 7,076 elements totally in the initial finite 
element model, and the adopted design parameters

in the initial finite element model are shown inTable

1.

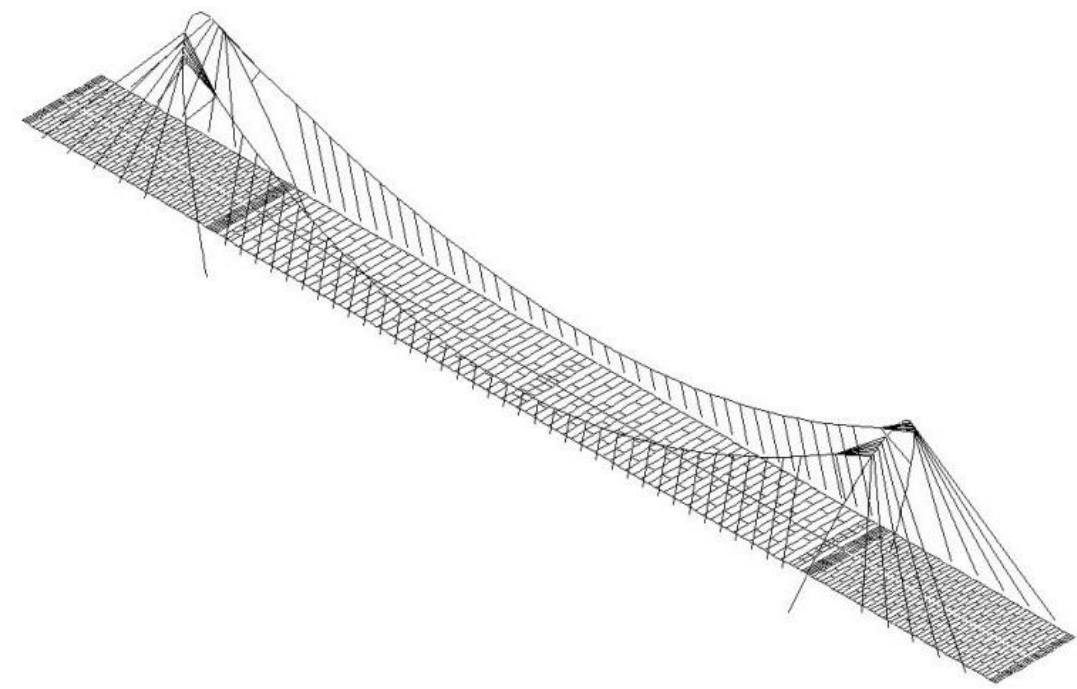

Fig.7. Initial Finite Element Model

Table 1Table of Material Parameters

\begin{tabular}{ccc}
\hline Material & $\begin{array}{c}\text { elasticity } \\
\text { modulus }(\mathrm{MPa})\end{array}$ & $\begin{array}{c}\text { mass density } \\
\left(\mathrm{Kg} / \mathrm{m}^{3}\right)\end{array}$ \\
\hline main cable & $1.98 \times 10^{5}$ & $7.85 \times 10^{3}$ \\
splayed maincable & $1.98 \times 10^{5}$ & $7.85 \times 10^{3}$ \\
suspender & $1.98 \times 10^{5}$ & $7.85 \times 10^{3}$ \\
stay-cable & $1.98 \times 10^{5}$ & $7.85 \times 10^{3}$ \\
pylon & $2.06 \times 10^{5}$ & $7.85 \times 10^{3}$ \\
girder & $2.06 \times 10^{5}$ & $7.85 \times 10^{3}$ \\
equivalent girder & $0.827 \times 2.06 \times 10^{5}$ & $7.85 \times 10^{3}$ \\
\hline
\end{tabular}

The structural responses which can be directly measured and own higher measurement accuracy are takeninto consideration as the objection responses[32]. Displacements of girder are measured directly by dial gauges, and their measured accuracies are guaranteed. Furthermore, the frequencies and mode shapes are extracted from the dynamic measurements, such as acceleration time-histories, aided by data-driven stochastic subspace identification (SSI) method [33], but identified frequencies are more accurate than the mode shape in light of the engineering measurement standpoint. Even though the cable tensions are measured directly by the force sensors, but their measurement accuracy are not ensured for the reason of zero-drift and temperature-drift. Hence, the measured girder displacements and identified frequencies are regarded as the objectiveresponses in the process of model updating.

The discrepancies between the measuredobjective responsesand the calculated results from the initial finite element modelare shown inTable 2. In this Table, $\mathrm{d}_{i}(i=1, \ldots, 9)$ isthe displacement due to the counterweight of main girderatmeasured point $i$ as shown in Fig. $2 ; \omega_{i}(i=1,2)$ means the vertical frequency, whereas the corresponding mode shape for $\omega_{i}$ are shown inFig.8.

The measured values whichare the average results of 10 times repeated tests in 3 days are shown in Table 2 along withtheir standard deviations (SD). The discrepancy in Table 2 is relative error betweenthe calculated results and experimental ones. Moreover,these 12 structural responsesshown in Table 2are regarded as the response features of the model bridge in its finite model updating procedure.

As shown in Table 2, there is a certain error between the predicted structural responsesfrom the initial finite element model and the corresponding experimental ones.The maximaldiscrepancy is $27 \%$ for the natural frequency, while the maximal deviationof displacement is $116 \%$ at $L_{2} / 4$ of the main span. Hence, it is essential to update the finite element model todecrease the discrepancy between the experimental results and the predicted structural responses. 
Table 2Predicted Structural Response Error of Initial Finite Element Model

\begin{tabular}{ccccc}
\hline features & $\begin{array}{c}\text { predicted } \\
\text { value }\end{array}$ & $\begin{array}{c}\text { measured } \\
\text { value }\end{array}$ & SD & discrepancy \\
\hline$\omega_{1}(\mathrm{~Hz})$ & 2.022 & 1.852 & 0.102 & $-9.13 \%$ \\
$\omega_{2}(\mathrm{~Hz})$ & 3.101 & 2.442 & 0.135 & $-27.00 \%$ \\
$\mathrm{~d}_{1}(\mathrm{~mm})$ & -3.485 & -1.616 & 0.078 & $-115.64 \%$ \\
$\mathrm{~d}_{2}(\mathrm{~mm})$ & -3.478 & -1.711 & 0.081 & $-103.27 \%$ \\
$\mathrm{~d}_{3}(\mathrm{~mm})$ & -6.593 & -6.706 & 0.192 & $1.68 \%$ \\
$\mathrm{~d}_{4}(\mathrm{~mm})$ & -6.589 & -6.590 & 0.129 & $0.01 \%$ \\
$\mathrm{~d}_{5}(\mathrm{~mm})$ & -8.541 & -11.082 & 0.167 & $22.93 \%$ \\
$\mathrm{~d}_{6}(\mathrm{~mm})$ & -8.540 & -10.527 & 0.146 & $18.87 \%$ \\
$\mathrm{~d}_{7}(\mathrm{~mm})$ & -6.601 & -7.000 & 0.066 & $5.70 \%$ \\
$\mathrm{~d}_{8}(\mathrm{~mm})$ & -6.600 & -7.116 & 0.029 & $7.24 \%$ \\
$\mathrm{~d}_{9}(\mathrm{~mm})$ & -3.492 & -2.101 & 0.021 & $-66.22 \%$ \\
\hline
\end{tabular}

1st Vertical Modal Shape
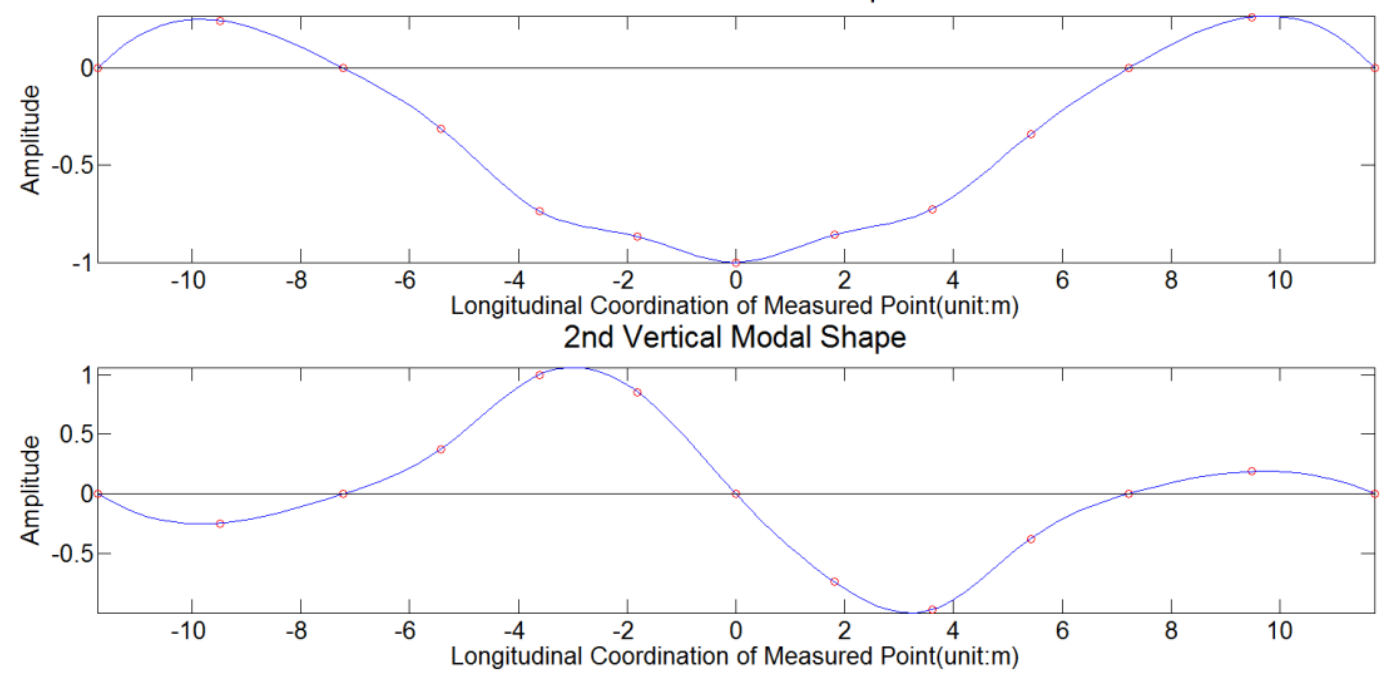

Fig.8.Mode shapes for first two vertical frequencies derived from measured data

\subsection{Undetermined Design Parameters}

There are two kinds of uncertainties in the finite model updating of the combined cable-stayed suspension bridge, namely material and structural uncertainty, and material uncertainty is discussed in this subsection, and the connection of different girder segments belongs to the structural uncertainty will be discussed in next subsection.

The main design parameters of combined cable-stayed suspension bridgeinclude the elastic moduli and mass densities for the main cable, the splayed-main cable, the suspender, the stay-cable,the pylon, the main girder and the equivalent connection girder.

Pylon, girder, main cable, splayed main cable, suspender and stay-cable are made of steel, and the material properties of steel, such as density and elastic modulus, can be obtained directly from the material test.
But the components of pylon and girder are different from the components of main cable, splayed main cable, suspender and stay-cable, there are linkages at each side of main cable, splayed main cable, suspender and stay-cable for assembling all these components into a whole bridge. And it means that the components of main cable, splayed main cable, suspender and stay-cable not only consist of spring steel wires, and the properties of all these components are not equal to the material properties of spring steel wire, then their properties, such as density and elastic modulus are regarded as the undermining parameters in this study.

\subsection{Substructures of Main Girder}

The bolts on the different connection plate at the end of the girder segment are tighten manually, the discreteness of the bolt tightness at the different connection plate cannot be ignored. If all of the equivalent connection girders in the model bridge 
are regarded as the same, it means that only one elastic modulus is updated during the model updating procedure, the discreteness of different bolts' tightness isn't taken into consideration. If each equivalent connection girder is taken as the different girder with different elastic modulus, the number of the updating elastic moduli only for the equivalent connection girder is 72 ; the difficulty of finite element model updating increases rapidly as the number of updating parameters increases. In order to ensure the computational efficiency of model updating and take the discreteness of bolts' tightness into consideration, the substructure model updating method is adopted to update the stiffness of equivalent connection girder. It means that the equivalent connection girder owning the identical stiffness of the stringer is regarded as the consistentcross-section.As shown in Fig.2, all of the girder segment connections are located at the main span, so the girder at main span is partitioned into 8 substructures.

The undetermined design parameters and the underdeterminedelastic modulus of equivalent connection of substructures are summarized in Table 3. In this table, $E_{i}$ and $\rho_{i}$ are the elastic modulus and the mass density of ith undetermined design parameter respectively.

Table 3List Table of Substructure/Component with undetermined parameters

\begin{tabular}{ccc}
\hline No. & Substructure/Component & Undetermined Parameter \\
\hline $\mathbf{1}$ & Substructure (1) & $\boldsymbol{E}_{\mathbf{1}}$ \\
$\mathbf{2}$ & Substructure (2) & $\boldsymbol{E}_{\mathbf{2}}$ \\
$\mathbf{3}$ & Substructure (3) & $\boldsymbol{E}_{\mathbf{3}}$ \\
$\mathbf{4}$ & Substructure (4) & $\boldsymbol{E}_{\mathbf{4}}$ \\
$\mathbf{5}$ & Substructure (5) & $\boldsymbol{E}_{\mathbf{5}}$ \\
$\mathbf{6}$ & Substructure (6) & $\boldsymbol{E}_{\mathbf{6}}$ \\
$\mathbf{7}$ & Substructure (7) & $\boldsymbol{E}_{\mathbf{7}}$ \\
$\mathbf{8}$ & Substructure (8) & $\boldsymbol{E}_{\mathbf{8}}$ \\
$\mathbf{9}$ & main cable & $\boldsymbol{E}_{\mathbf{9}}$ \\
10 & splayed main cable & $E_{10}$ \\
11 & suspender & $E_{11}$ \\
$\mathbf{1 2}$ & stay-cable & $\boldsymbol{E}_{\mathbf{1 2}}$ \\
13 & main cable & $\rho_{1}$ \\
14 & splayed main cable & $\rho_{2}$
\end{tabular}

\begin{tabular}{lll}
15 & suspender & $\rho_{3}$ \\
16 & stay-cable & $\rho_{4}$ \\
\hline
\end{tabular}

\subsection{Response Surface Model}

\section{Test Design}

As shown inTable 3, the total number of indeterminate design parameters are 16, and 59 values for each designing parameter are assigned according to itsvalue range discussed in section 0 . It means that the discussed issue is a test design with 16 factors and 59 levels. At least $59^{2}=3481$ tests are required by orthogonal design method, and the essential test number by homogeneous design method isonly $16 \times 59=944$. Obviously, the required test number of homogeneous design is far less than that of orthogonal design. The homogeneous design method[34]is adopted to obtain sample points of indeterminate design parameters.

Hereby, the samples of all the indeterminate parameters for the combined cable-stayed suspension model bridge are obtained, and their distribution is shown inFig.10. As shown in this figure, the samples are in the uniform distribution and all of test levels are covered.

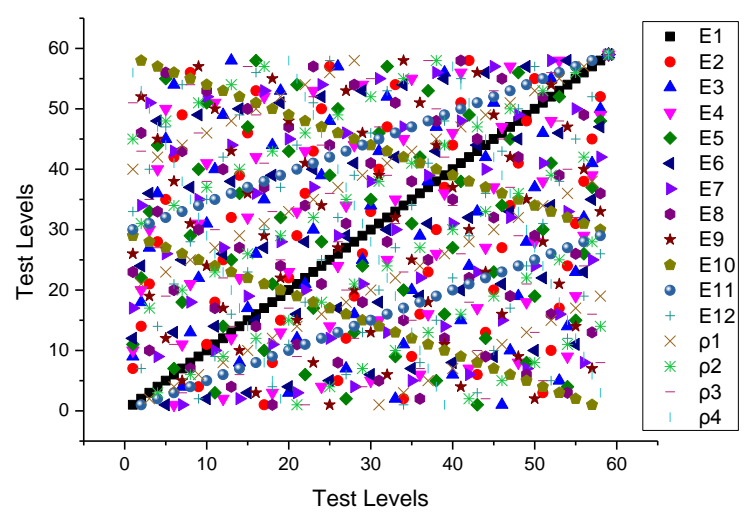

Fig.9. Samples Distribution

\section{Significance Test and Fitting}

The structural responses corresponding to sample points shown inFig.9 are obtained through FEM analysis, and F-test shown in Eq.(2)is adopted to determine the significance of the indeterminate parameters. The result of significance test showsthat the mass densities of the main cable, the suspender, the splayed main cable and stay-cable $\rho_{i}(i=1 \sim 4)$, the elastic moduli of main cable $E_{10}$ and the splayed main cable $E_{11}$ have no remarkable impacts on the 
overall structural responses as shown in Table 2; the other parameters $E_{1} \sim E_{9}$ and $E_{12}$ have significant impacts on the structural responses, as shown in bold font in Table 3, and among them 10 parameters are selected from all the 16 design parameters as the indeterminate parameters.

The result of the significance test for the structural response $\omega_{2}$ to all of the indeterminatedesign parameters is shown in Fig.10, the significant threshold is also shown in this figure, the values of significant coefficients histogram are less than threshold,thus indicate that the corresponding design parametersbelong to most plausible class of parameters[35], and it means parameters $E_{1} \sim E_{9}$ and $E_{12}$ are significant parameters on the structural response $\omega_{2}$.

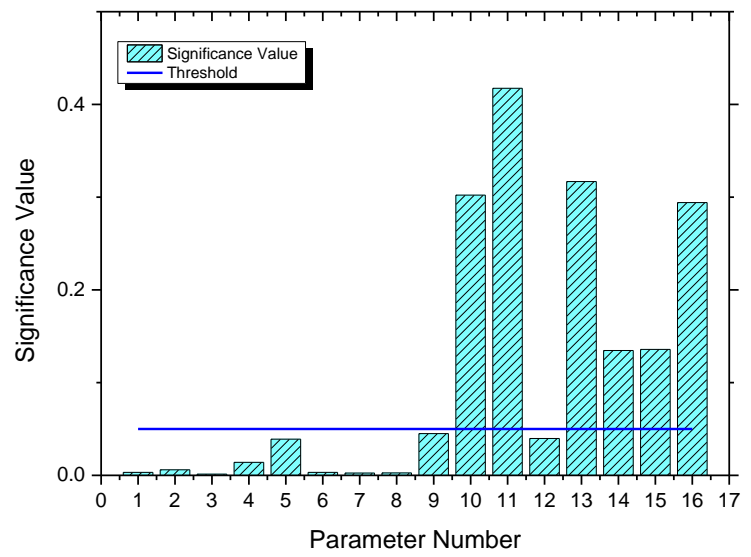

Fig.10.Significance test of undetermined Design Parameters on the Response of $\omega_{2}$

It can be seen that parameters $E_{1} \sim E_{9}$ and $E_{12}$ are significant parameters on the structural responses, then the response surface function formula is retrieved according to Eq.(3):

$$
Y=\beta_{0}+\sum_{i=1}^{9} \beta_{i} E_{i}+\beta_{10} E_{12}+\sum_{i=1}^{9} \beta_{i+10} E_{i}^{2}+\beta_{20} E_{12}^{2}
$$

where, $E_{i}$ is significant parameters on the structural responses, $Y$ indicates the response surface function, $\beta_{i}(i=0,1, \ldots, 20)$ is the 21 undetermined coefficients.

\section{Validation}

After the response surface modelsare achieved through the regression analysis, R-square Statistic [34] shown in Eq.(4)and Relative Mean Square Error shown in Eq.(5)areadopted toverify the fitted response surface models, and the validation resultsare shown in

Table 4. This table also shows that the accuracies of the fitted 12 response surface models are granted.

Table 4 Validation Results for the fitted Response Surface Models

\begin{tabular}{ccc}
\hline Structural Responses & $\mathrm{R}^{2}$ index & RMSE index \\
\hline$\omega_{1}$ & 0.9881 & $1.72 \mathrm{E}-30$ \\
$\omega_{2}$ & 0.9936 & $1.40 \mathrm{E}-35$ \\
$d_{1}$ & 0.9950 & $1.39 \mathrm{E}-37$ \\
$d_{2}$ & 0.9907 & $1.53 \mathrm{E}-32$ \\
$d_{3}$ & 0.9968 & $3.15 \mathrm{E}-41$ \\
$d_{4}$ & 0.9915 & $2.62 \mathrm{E}-33$ \\
$d_{5}$ & 0.9941 & $2.75 \mathrm{E}-36$ \\
$d_{6}$ & 0.9885 & $9.30 \mathrm{E}-31$ \\
$d_{7}$ & 0.9886 & $7.49 \mathrm{E}-31$ \\
$d_{8}$ & 0.9740 & $4.36 \mathrm{E}-24$ \\
$d_{9}$ & 0.9815 & $7.32 \mathrm{E}-27$ \\
\hline
\end{tabular}

\subsection{Model Updating Results}

The determinationof the response surface function is equivalent to the determination of $\beta_{i}$ in Eq.7, and this kind of decision making is a constrained optimization problem. Genetic algorithm[36]is an efficient and effective algorithm to solve this kind optimization problem, therefore genetic algorithm is adopted to obtain the response surface functions in this paper.The experimental measurements are regardedas the target values, the optimization of the fitted response surface models is carried out in the value space of the design parameters, and the optimization results for indeterminate design parameters are shown in Table 5 . The updating ratio $\zeta$ of design parameter in Table 5 is defined as $\zeta=\left(P-P_{0}\right) / P_{0} \times 100 \%$; where, $P_{0}$ is the initial value of design parameter, $P$ is the updated value of design parameter. As shown in Table 5, only the elastic modulus of the stay-cable $E_{12}$ is less than its initial value, the values of other updated parameters are greater than their initial values; and the maximal updating ratio is $5 \%$ approximately. It means that the design parameters are updated in the rational range, and the physical meanings of design parameters are ensured.

Table 5 updating ratio of design parameters

\begin{tabular}{cccc}
\hline parameters & $\zeta$ & parameters & $\zeta$ \\
\hline$E_{1}$ & $2.96 \%$ & $E_{6}$ & $2.96 \%$
\end{tabular}




\begin{tabular}{llll}
\hline$E_{2}$ & $2.74 \%$ & $E_{7}$ & $2.93 \%$ \\
$E_{3}$ & $2.76 \%$ & $E_{8}$ & $1.96 \%$ \\
$E_{4}$ & $0.86 \%$ & $E_{9}$ & $4.77 \%$ \\
$E_{5}$ & $1.08 \%$ & $E_{12}$ & $-2.56 \%$ \\
\hline
\end{tabular}

By substituting the updated design parameters into the original design parametersin the initial finite element model to obtain the updated finite model of the combined cable-stayed suspension bridge, and the predicted structural responses are achieved, asshown in Table 6 . The errors between the predicted values and their corresponding measurements after the finite element model updating are also shown in Table 6. Comparing the errors in Table 6with the counterparts in Table 2, it is shown that the discrepancies between the calculated values and the measured value are reduced considerably; the errors of natural frequencies is less than $3 \%$ after model updating, and the error of displacements are slightly greater than that of natural frequencies but they are all less than 5\%. The predicted values and their measurements of the first $3^{\text {rd }}$ to $6^{\text {th }}$ natural frequencies and their error are also shown in Table 6.

Table 6 Error after FEM Updating

\begin{tabular}{llll}
\hline response & measurement & calculated value & error \\
\hline$\omega_{1}$ & 1.852 & 1.878 & $1.40 \%$ \\
$\omega_{2}$ & 2.442 & 2.385 & $-2.33 \%$ \\
$\omega_{3}$ & 2.816 & 2.793 & $-0.82 \%$ \\
$\omega_{4}$ & 3.859 & 3.789 & $-1.81 \%$ \\
$\omega_{5}$ & 4.676 & 4.810 & $2.87 \%$ \\
$\omega_{6}$ & 5.634 & 5.762 & $2.27 \%$ \\
$d_{1}$ & -1.616 & -1.676 & $3.71 \%$ \\
$d_{2}$ & -1.711 & -1.7481 & $2.17 \%$ \\
$d_{3}$ & -6.706 & -6.864 & $2.36 \%$ \\
$d_{4}$ & -6.590 & -6.386 & $-3.10 \%$ \\
$d_{5}$ & -11.082 & -10.875 & $-1.87 \%$ \\
$d_{6}$ & -10.527 & -10.214 & $-2.97 \%$ \\
$d_{7}$ & -7.000 & -7.237 & $3.39 \%$ \\
$d_{8}$ & -7.116 & -6.953 & $-2.29 \%$ \\
$d_{9}$ & -2.101 & -2.202 & $4.81 \%$ \\
\hline
\end{tabular}

As shown inTable 5 , the 1 st and 2 nd vertical frequencies are smaller than those of the initial finite element model, while the elastic modulus of stay-cables decreases and the elastic moduli of other parameters increase. The stiffness variation of stay-cables makesmore impact on the vertical stiffness of the whole bridge in comparison with the stiffness variation of main cable and girder[37]. Consequently, the 1st and 2 nd vertical frequencies decrease along with the smaller elastic modulus of stay-cables, even though the elastic modulus of main cable and girder is increased slightly.

In order to understand the internal force status, the comparative analysis between the predicted cable tensions from the updated finite element model and the measured cable forces arealso carried out. All the cable tensions for the suspender, the splayed main cable and stay-cable are jointed end to end to compose a 61-dimensional vector, and the similarity between the predicted cable tensions and the measured cable tensions are figured out by the method shown in Eq.(8); and the similarities of cable tensions for upstream cables and downstream cables are 0.99975 and 0.99964 respectively. It is shown that the predicted internal cable tensionfrom the updated finite element model are in good agreement with the one obtainedfrom the experiment. The comparison diagram between the predicted cables tensions of suspenders and the measured cable tensions of suspenders is shown in

Fig.11. It is shown that the cable forces are relatively uniform as a whole, and the maximal error is $-4.76 \%$ occurred in the $37 \#$ downstream suspender.

$$
\cos (x, y)=\frac{(x, y)}{\|x\| \times\|y\|}=\frac{\sum_{i=1}^{n} x_{i} \times y_{i}}{\left(\sum_{i=1}^{n} x_{i}^{2} \times \sum_{i=1}^{n} y_{i}^{2}\right)^{\frac{1}{2}}}
$$

Where, $x$ and $y$ are the vectors of cable tensions for the prediction and the measured cable tensionrespectively on the upstream side and downstream side simultaneously. 


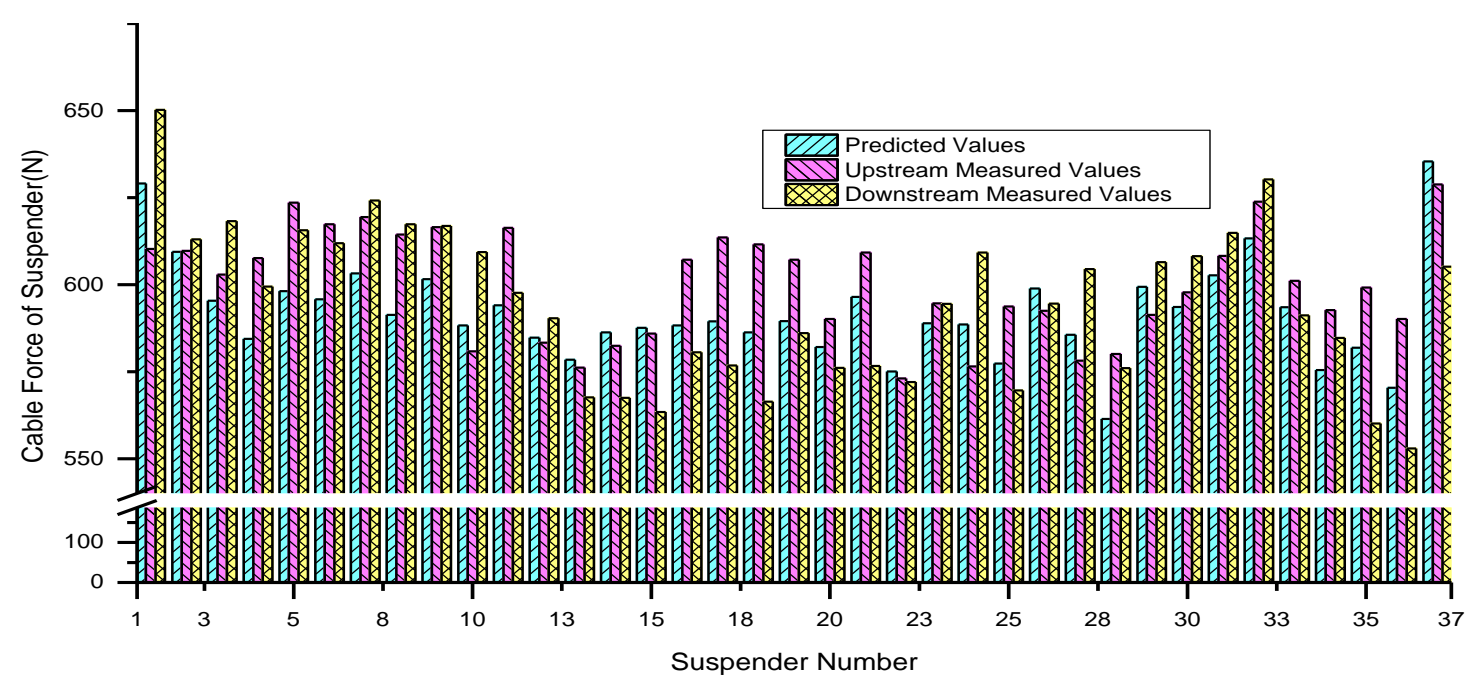

Fig.11. Cable Forces Comparison Diagram of Suspenders after Model Updating

\section{Conclusion}

A novel finite element model updating by combiningthe substructure model updating method with the response surface model updating method is proposed in this paper to update the finite element model of a certain combined cable-stayed suspension bridge, the following conclusions can be drawn based on the above analysis and discussion.

1) The advantages of substructure and response surface model for finite element model updating are fully utilized in the proposed model updating method, and the finite element model updating of large-scale and complex bridge structure is achieved aided by the proposed method;

2) The introduction of substructure model updating ismore in line with the actual situation of the large-scale and complex bridge structure, such as the combined cable-stayed suspension bridge. Although the count of updating design parameters is increased inevitably, the calculation efficiency of the proposed method still can be guaranteed;

3) It is depicted from the model bridge experiment that the discrepancies between predicted values and measured values are well consistent with each other after the finite element model updating, and there is no excessive modification of the design parameter. The feasibility and effectiveness of the proposed method is verified by the laboratory experiment of a certain combined stayed-cable suspension model bridge.

\section{Acknowledgement}

The research reported here has been conducted as part of the result of a series of research projects granted by the National Key Basic Research and Development Plan (973 Program) with 2013CB036302, National Science Foundation with 51078316,Sichuan Science and Technology Program with 2011JY0032, Railway Ministry Science and Technology Research and Development Program with 2011G026-E \& 2012G013-C.

\section{Reference}

[1] Farrar C R, Worden K. Structural health monitoring; a machine learning perspective[M]. United Kingdom: John Wiley \& Sons, Ltd., 2013.

[2] Catbas FN, Kijewski-Correa T, Aktan AE. Structural identification (St-Id) of constructed facilities: approaches, methods and technologies for effective practice of St-Id [M]. Virginia: ASCE and American Society of Civil Engineers, 2013.

[3] Catbas N, Gokce H B, Frangopol D M. Predictive Analysis by Incorporating Uncertainty through a Family of Models Calibrated with Structural Health-Monitoring Data [J]. Journal of Engineering Mechanics. 2013, 139(6): 712-723. 
[4] Shahidi S G, Pakzad S N. Effect of measurement noise and excitation on Generalized Response Surface Model Updating[J]. Engineering Structures. 2014, 75: 51-62.

[5] Marwala T. Finite-element-model Updating Using Computational Intelligence Techniques-Applications to Structural Dynamics [M]. London: Springer-Verlag London Limited, 2010.

[6] Moaveni B, Conte J P, Hemez F M. Uncertainty and sensitivity analysis of damage identification results obtained using finite element model updating [J]. Computer - Aided Civil and Infrastructure Engineering, 2009, 24(5): 320-334.

[7] Jaishi B, Ren W X. Structural finite element model updating using ambient vibration test results [J]. Journal of Structural Engineering, 2005, 131(4): 617-628.

[8] Zhang Q W, Chang C C, Chang T Y P. Finite element model updating for structures with parametric constraints $[\mathrm{J}]$. Earthquake engineering \& structural dynamics, 2000, 29(7): 927-944.

[9] Jaishi B, Ren W X. Damage detection by finite element model updating using modal flexibility residual [J]. Journal of sound and vibration, 2006, 290(1): 369-387.

[10] Lu Y, Tu Z. A two-level neural network approach for dynamic FE model updating including damping[J]. Journal of Sound and Vibration, 2004, 275(3): 931-952.

[11] Ren, W., S. Fang and M. Deng, Response Surface-Based Finite-Element-Model Updating Using Structural Static Responses. Journal of Engineering Mechanics, 2011. 137(4): p. 248-257.

[12] Ren, W., H. Chen, Finite element model updating in structural dynamics by using the response surface method. Engineering Structures, 2010. 32(8): p. 2455-2465.

[13] Cross, E.J., et al., Long-term monitoring and data analysis of the Tamar Bridge. Mechanical Systems and Signal Processing, 2013. 35(1-2): p. 16-34.

[14] Zhou L, Yan G, Ou J. Response Surface Method Based on Radial Basis Functions for Modeling Large-Scale Structures in Model Updating[J]. Computer-Aided Civil and Infrastructure Engineering. 2013, 28(3): 210-226.

[15] Deng, L. and C.S. Cai, Bridge Model Updating Using Response Surface Method and Genetic Algorithm. Journal of Bridge Engineering, 2010. 15(5): p. 553-564.
[16] Li X, Zhang D, Yan W, et al. Effects of model updating on the estimation of stochastic seismic response of a concrete-filled steel tubular arch bridge[J]. Structure and Infrastructure Engineering. 2013: 1-18.

[17] Bakir P G, Reynders E, De Roeck G. Sensitivity-based finite element model updating using constrained optimization with a trust region algorithm [J]. Journal of Sound and Vibration, 2007, 305(1): 211-225.

[18] Yu E, Taciroglu E, Wallace J W. Parameter identification of framed structures using an improved finite element model - updating method-Part I: formulation and verification [J]. Earthquake Engineering \& Structural Dynamics, 2007, 36(5): 619-639.

[19] Chakraborty S, Sen A. Adaptive response surface based efficient Finite Element Model Updating [J]. Finite Elements in Analysis and Design. 2014, 80: 33-40.

[20] Liu, Y., H. Sun and D. Wang, Updating the Finite Element Model of Large-Scaled Structures using Component mode Synthesis Technique. Intelligent Automation and Soft Computing, 2013. 19(1): 11-21.

[21] Liu Y, Li Y, Wang D, et al. Model Updating of Complex Structures Using the Combination of Component Mode Synthesis and Kriging Predictor[J]. The Scientific World Journal. 2014, 2014: 1-13.

[22] Papadimitriou C, Papadioti D. Component mode synthesis techniques for finite element model updating [J]. Computers \& Structures. 2013, 126: 15-28.

[23] Moaveni, B. and I. Behmanesh, Effects of changing ambient temperature on finite element model updating of the Dowling Hall Footbridge. Engineering Structures, 2012. 43: 58-68.

[24] Weng, S., et al., Substructure based approach to finite element model updating. Computers \& Structures, 2011. 89(9-10): p. 772-782.

[25] Ding Dehao, finite element model updating of research of single pylon cable-stayed bridges, Southwest Jiaotong University. 2012:84.

[26] Shan Deshan, Finite Element Model Updating of Single Pylon Cable-Stayed Bridges Based on RBF-ANN. Journal of Chongqing Jiaotong university, 2013, 32(4): 555-560

[27] Wang T, Cheng C, Guo X. Model-based predicting and correcting algorithms for substructure online hybrid tests [J]. Earthquake Engineering \& Structural Dynamics. 2012: 2331-2349 
[28] Thomas P. Ryan. Modern Regression Methods [M]. Wiley-Interscience, $2^{\text {nd }}$ Edition, 2009

[29] Yuen K V, Katafygiotis L S. Substructure identification and health monitoring using noisy response measurements only [J]. Computer - Aided Civil and Infrastructure Engineering, 2006, 21(4): 280-291.

[30] Lam H F, Yin T. Dynamic reduction-based structural damage detection of transmission towers: Practical issues and experimental verification [J]. Engineering Structures, 2011, 33(5): 1459-1478.

[31] Wang Y Y. Theory and Application of Dynamic Substructure Method [M]. Beijing: Science Press, 1999 (in Chinese)

[32] DaeSung Jung, ChulYoung Kim. Finite element model updating of a simply supported skewed PSC I-girder bridge using Hybrid Genetic Algorithm [J]. KSCE Journal of Civil Engineering, 2013. 17(3): 518-529

[33] Au SK, Ni YC, Zhang F L, Lam H F. Full-Scale Dynamic Testing and Modal Identification of a Coupled Floor Slab System [J], Engineering Structures, 2012, 37: 167-178.

[34] SongsongSun. Finite Element Model Updating Research of Combined Cable-Stayed Suspension Bridges [D]. Chengdu: Southwest Jiaotong University, 2013 (in Chinese)

[35] Beck J L, Yuen K V. Model selection using response measurements: Bayesian probabilistic approach [J]. Journal of Engineering Mechanics, 2004, 130(2): 192-203.

[36] Goldberg, D.E., Genetic Algorithms in Search, Optimization, and Machine Learning [M]. London: Pearson Education, 2013

[37] Bruno D, Greco F, Lonetti P. A parametric study on the dynamic behavior of combined cable-stayed and suspension bridges under moving loads [J]. International Journal for Computational Methods in Engineering Science and Mechanics, 2009, 10(4): 243-258. 